\title{
AN ISOTOPIC METHOD OF ESTIMATING CONDUCTIVE HEAT FLUX THROUGH ANTARCTIC FIRST-YEAR SEA ICE
}

\author{
by
}

\author{
R. Souchez, J. -L. Tison
}

(Faculté des Sciences, C.P. 160, Université Libre de Bruxelles, B-1050 Bruxelles, Belgium)

\author{
and \\ J. Jouzel
}

(Laboratoire de Géochimie Isotopique, CEN, Saclay, F-91191 Gif-sur-Yvette, France, and DLPC, Laboratoire de Glaciologie et de Géophysique de l'Environnement, BP 96, 38402 Saint-Martin-d'Hères Cedex, France)

\section{ABSTRACT}

The deuterium concentration profile in a first-year Antarctic sea-ice cover is used to deduce a growth-rate curve, applying a previously published model. Time variations of the conductive heat flux throughout the growth period are then estimated from this growth-rate curve. Results indicate that the isotopic determination of sea ice growth rate can be considered as an alternate method for determining the conductive heat flux through a young sea-ice cover. However, there is need for a further test of the method by measuring in situ temperatures and growth rates during the formation of first-year sea ice, and by analyzing the isotopic composition of ice samples taken simultaneously along selected profiles during the growth period.

\section{INTRODUCTION}

Deuterium concentration in sea ice is dependent on the freezing rate. Distribution of a heavy isotope species in ice during water freezing is related to its distribution in the sea water immediately adjacent to the freezing front. A boundary layer where mass transport is taking place only by diffusion exists at the interface. Taking this into account in a box diffusion model, Souchez and others (1987) were able to predict the isotopic distribution in the ice in the course of freezing for a given freezing rate. In a later paper (Souchez and others, 1988), this model was used to determine first-year Antarctic sea-ice growth rates by considering a water reservoir where the deuterium concentration is kept constant by convective mixing at its initial value during progressive freezing. If the evolution of the sea-ice cover is the result of thermodynamic processes rather than dynamic ones, the growth rates deduced from the isotopic profile can be used for estimating the time variations of the conductive heat flux through the ice.

HDO concentrations will be denoted hereafter in $\delta$ units versus VSMOW (Vienna Standard Mean Ocean Water). They are expressed in per mil for $\delta D$, i.e.:

$$
\delta_{\mathrm{D}}=1000 \frac{R_{\text {sample }}-R_{\mathrm{vSMOW}}}{R_{\text {vSMOW }}}
$$

where $R_{\text {sample }}$ and $R_{\text {ySMOW }}$ are the isotopic ratios of the sample and of the VSMOW, respectively. The samples were analyzed at the Centre d'Etudes Nucléaires de Saclay, France. The accuracy of the measurements is $0.5 \%$ on $\delta \mathrm{D}$.

\section{CORE LOCATION AND STRATIGRAPHY}

First-year sea ice was sampled in Breid Bay during December 1986. Breid Bay is located on Prinsesse Ragnhild $\mathrm{K} y s t$ in East Antarctica. It is surrounded by floating glacier ice and can be considered as a bay in an ice shelf. Location of the sampling site is $70^{\circ} 13^{\prime} \mathrm{S}$ and $23^{\circ} 47^{\prime} \mathrm{E}$. Breid Bay was free of ice at the end of the summer preceding the sampling season. Therefore the sea-ice cover studied is first-year sea ice. It was a continuous flat cover at the time of sampling, with about $0.40 \mathrm{~m}$ of blown snow on top of the ice sequence. This snow is considered to be a late addition. No sign of rafting and ridging was detected.

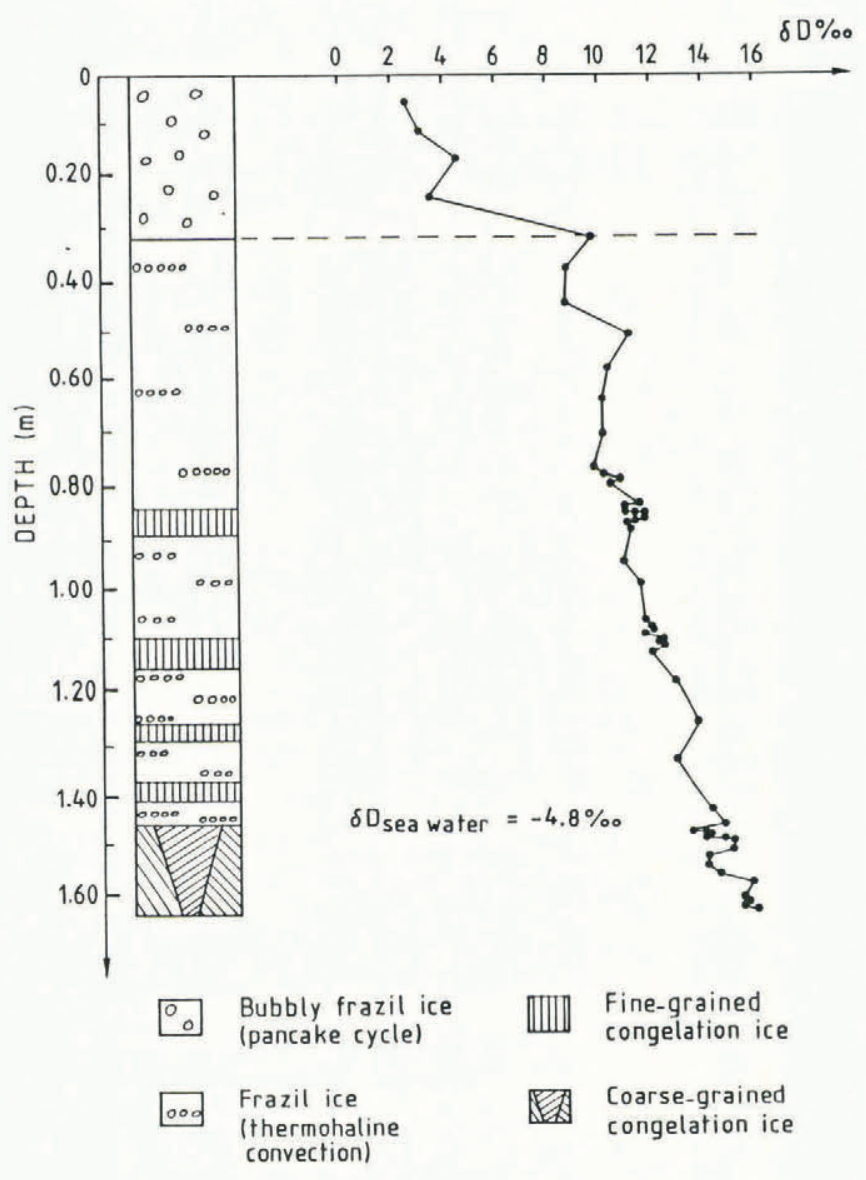

Fig. 1. Stratigraphy and $6 \mathrm{D}$ profile versus depth in the studied ice core. 
However, the development of a certain amount of rafting is a possibility during the formation of the initial, discontinuous ice cover.

The ice core analyzed here is $1.64 \mathrm{~m}$ long. Because of the $0.40 \mathrm{~m}$ of dry snow over it, sea water was reached at a depth of $2.04 \mathrm{~m}$. The uppermost $0.32 \mathrm{~m}$ of the core consists of bubbly, fine-grained, equigranular ice which could be associated with the "pancake cycle" studied by Lange and others (1989) during the first stage of sea-ice formation in open water conditions. The deuterium concentration in this ice rules out formation by infiltration of snow cover, as indicated by Souchez and others (1988). Below $0.32 \mathrm{~m}$, interbedded frazil and congelation ice layers occur with the latter more frequent in the second part of the core (Fig. 1). The limits between the textural units are parallel to each other, sub-horizontal, with clear contacts. No voids or mylonitization zones have been observed. Tison and Haren (1989) have developed arguments indicating that, in this case, dynamic effects cannot explain the interbedding of frazil and congelation ice.

\section{ISOTOPES AND GROWTH RATES}

Isotopic determination of sea-ice growth rates is likely to be more accurate than determination based on the salinity profile, since it is less affected by brine entrapment and brine drainage mechanisms.

The gas content of sea ice appears to be very limited in the main part of the core since, below $0.32 \mathrm{~m}$, only a few bubbles are visible in thin sections. Neglecting this gas content, the relative brine volume can be calculated from the equations given in Cox and Weeks (1983). Using the $\mathrm{Na}$ content of the ice - determined by atomic absorption spectrophotometry - and the relative concentration of $\mathrm{Na}$ in sea water, the highest global salinity of congelation ice in the core can be estimated to be $1.8 \%$. The ice density is calculated at the $1.8 \%$ salinity level and then the relative brine volume. The value obtained for this volume at $-2{ }^{\circ} \mathrm{C}$ is $4.3 \%$. The isotopic composition of brine water can be considered as identical to that of sea water. Knowing the $\delta \mathrm{D}$ of sea water at the site $(-4.8 \% \circ)$ and the measured $\delta \mathrm{D}$ value of the congelation ice layer with the highest salinity $(11.8 \%)$, the $\delta_{\mathrm{i}} \mathrm{D}$ value of the ice itself, excluding the brines, can be calculated:

$$
0.957 \delta_{\mathrm{i}} \mathrm{D}+[0.043(-4.8 \%)]=11.8 \%
$$

This gives $\delta_{i} D=12.55 \%$ instead of the measured value of $11.8 \%$. The difference of $0.75 \%$ is very close to the accuracy of the mass spectrometer measurements $(0.5 \%$ in $\delta \mathrm{D})$. Brine movement due to gravity drainage and/or brine expulsion is unlikely to modify the isotopic composition of brine water. Furthermore, gravity drainage is considered to become negligible for a relative brine volume lower than 5\% (Weeks and Ackley, 1986).

Rate of migration of the freezing front in sea water can be deduced from the $\delta D$ profile shown in Figure 1. The trend of increased $\delta D$ values in congelation ice downwards along the core represents the general decrease in growth rates with depth. The highest $\delta \mathrm{D}$ value obtained in the bottom of the core, if compared to sea water underneath, corresponds closely to the maximum shift due to fractionation between water and ice. If the equilibrium fractionation coefficient for deuterium is taken as 1.0208 (Arnason, 1969), the observed shift of $20.7 \%$ is only $0.1 \%$ apart from the maximum possible theoretical value. This indicates not only a very low freezing rate but also that no subsequent melting occurred at the bottom of the core.

The $\delta D$ values in interbedded frazil layers do not deviate significantly from the trend given by the $\delta D$ values in congelation ice layers. This can be explained if frazil layers are produced by a thermohaline convection process since, in this case, frazil growth is largely determined by the same factors as those governing the development of congelation ice (Tison and Haren, 1989).

A growth curve for the sea-ice cover is displayed in Figure 2, using the isotopic profile in the box diffusion model of Souchez and others (1987). This curve gives the growth rate versus depth.

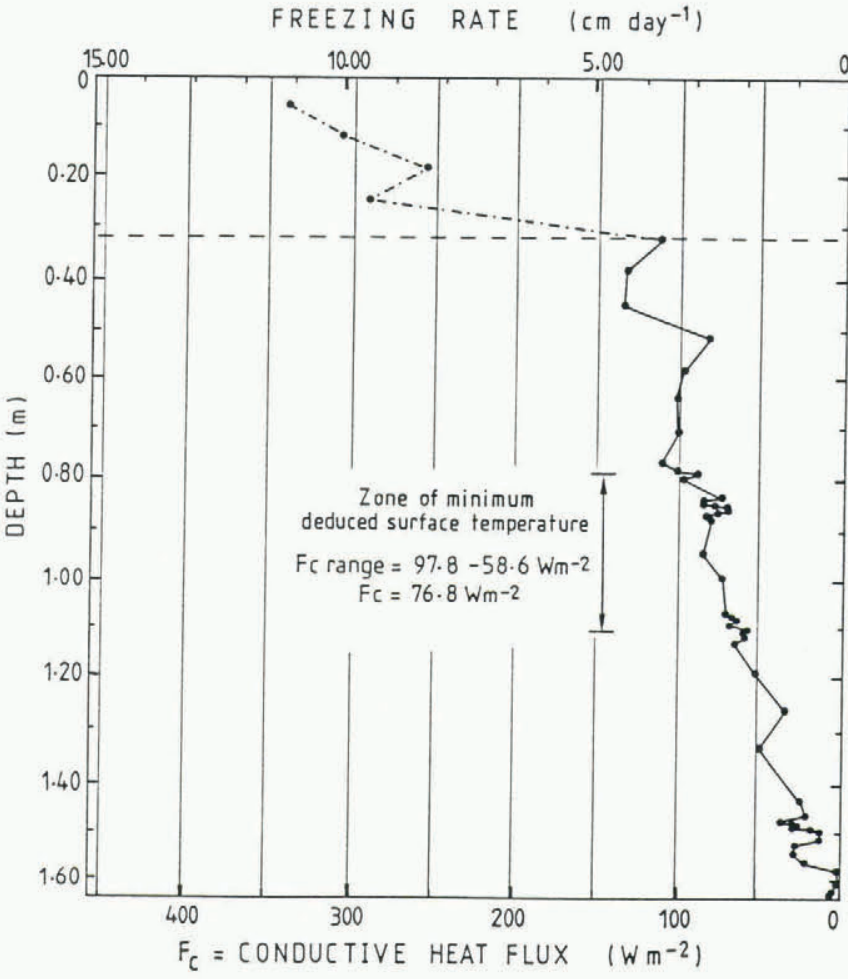

Fig. 2. Deduced freezing rates and conductive heat flux versus depth in the studied ice core.

\section{CONDUCTIVE HEAT FLUX ESTIMATED FROM THE} ISOTOPIC PROFILE

Several thermodynamic models have been proposed to describe the evolution of first-year sea ice, for example, Maykut (1978), Allison (1979), Nakawo and Sinha (1981), and Maykut (1986). In all of them, ice growth or ablation at the bottom of the ice cover is controlled by:

$$
F_{\mathrm{c}}+F_{\mathrm{w}}=\frac{k_{\mathrm{i}}\left(T_{0}-T_{\mathrm{F}}\right)}{H}+F_{\mathrm{w}}=-\rho_{\mathrm{i}} L \Delta H / \Delta t
$$

where $F_{\mathrm{c}}$ is the heat flux through the ice cover (conductive heat flux); $F_{\mathrm{w}}$ is the heat flux from the ocean to the bottom of the ice cover (oceanic heat flux); $H$ is the thickness of the ice; $k_{\mathrm{i}}$ is the thermal conductivity of sea ice $\left(2.1 \mathrm{~W} \mathrm{~m}^{-1} \mathrm{deg}^{-1}\right) ; T_{0}$ is the temperature at the surface of the ice cover; $T_{F}$ is the freezing point of sea water $\left(-1.9^{\circ} \mathrm{C}\right) ; \rho_{\mathrm{i}}$ is the density of sea ice $\left(900 \mathrm{~kg} \mathrm{~m}^{-3}\right) ; L$ is the latent heat of fusion $\left(2.93 \times 10^{5} \mathrm{~J} \mathrm{~K}^{-1}\right)$; and $t$ is the time. $F_{\mathrm{c}}>F_{\mathrm{w}}$ implies growing ice at the bottom releasing the required latent heat.

Since the growth rate $(\Delta H / \Delta t)$ at a given depth $(H)$ is known from the $\delta \mathrm{D}$ profile in the Breid Bay core, the heat flux related to ice growth can be calculated from the right term of Equation (1). It is shown, in $\mathrm{W} \mathrm{m}^{-2}$, as a function of ice thickness in Figure 2. This heat flux can be considered as equivalent to the conductive heat flux through the ice if, following Nakawo and Sinha (1981), it is assumed that the oceanic heat flux is negligible $\left(F_{\mathrm{w}} \ll F_{\mathrm{c}}\right)$. Allison (1981) inferred $F_{\mathrm{W}}$ values beneath seasonal ice near Molodezhnaya in East Antarctica $\left(67^{\circ} 40^{\prime} \mathrm{S}, 45^{\circ} 51^{\prime} \mathrm{E}\right)$ of $50 \mathrm{~W} \mathrm{~m}^{-2}$ during the first days of freezing, dropping to $10 \mathrm{~W} \mathrm{~m}^{-2}$ after that period. These values are modest if compared to the calculated values plotted in Figure 2. Nevertheless, the latter values will have to be considered as minimum estimates of the conductive heat flux.

A marked shift is clearly visible between the heat flux values of the uppermost $0.32 \mathrm{~m}$ of the core $\left(250-350 \mathrm{~W} \mathrm{~m}^{2}\right)$ and those in the main part $\left(<140 \mathrm{~W} \mathrm{~m}^{-2}\right)$. The shift corresponds to a sharp structural discontinuity associated with the transition from the "pancake cycle" to a continuous ice cover. As the "pancake cycle" is believed to develop by 


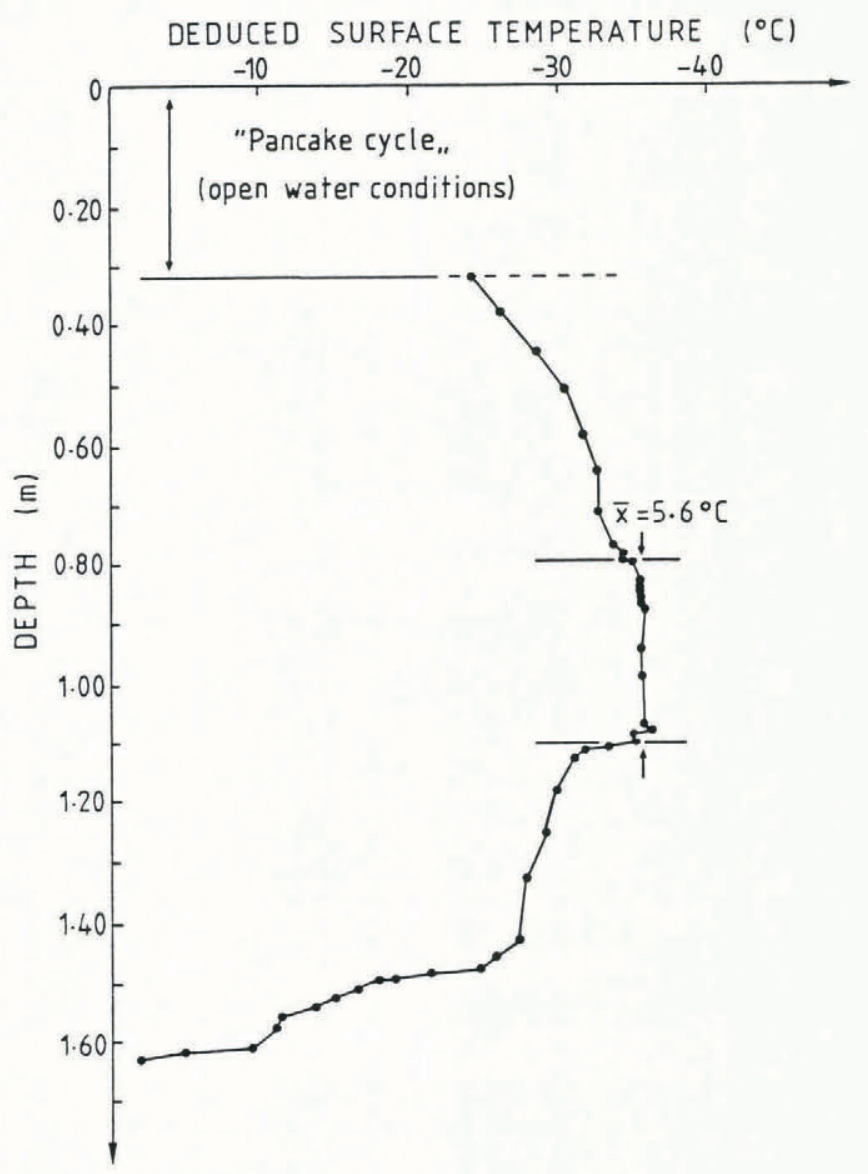

Fig. 3. Deduced surface temperatures versus depth in the studied ice core.

repeated rafting of ice covers a few $\mathrm{cm}$ thick (Lange and others, 1989), the flux should be quite constant and in accordance with that estimated in near-open-water conditions. Table 5.6, in Maykut (1986) gives calculated conductive heat flux in the central Arctic for various ice thickness categories. A value of $300-350 \mathrm{~W} \mathrm{~m}^{-2}$ is in the range for a $0.05-0.10 \mathrm{~m}$ ice thickness, in the beginning of the winter season.

The conductive heat flux subsequently decreases as the ice cover increases in thickness; small-scale fluctuations indicate that congelation ice layers are generally associated with slightly lower flux values. This flux across the ice cover implies a temperature difference between the freezing point of sea water at the bottom and a lower temperature of the ice surface which can be estimated from Equation (1). Figure 3 gives deduced surface temperatures versus sea water-ice interface positions for the whole profile below $0.32 \mathrm{~m}$. The curve has been smoothed to damp highfrequency temperature fluctuations. It shows a nearly constant minimum value of temperature between 0.80 and $1.10 \mathrm{~m}$ depth. The conductive heat flux at these depths fluctuates between 97.8 and $58.6 \mathrm{~W} \mathrm{~m}^{-2}$, with a mean value of $76.8 \mathrm{~W} \mathrm{~m}^{-2}$. Table 5.6 in Maykut (1986) shows a value of $75 \mathrm{~W} \mathrm{~m}^{-2}$ for an ice thickness of $0.8 \mathrm{~m}$ during the coldest month of the winter season in the central Arctic when surface temperatures are very similar to the ones recorded at the now-disappeared Roi Baudouin Station, close to Breid Bay (Meerburg, 1968). The two values agree fairly well.

\section{CONCLUSION}

Results indicate that the isotopic method can be a valuable approach to conductive heat flux studies. However, this study must be exposed to further critical tests. In-situ growth rate measurements, ice, air, and water temperature recordings and snow cover thickness determinations must be carried out during the period of formation of a young seaice cover. Simultaneously ice and water must be sampled underneath for their isotopic composition and salinity. Such a study would allow us to estimate the potential of the isotopic method.

\section{ACKNOWLEDGEMENTS}

Dr H. Decleir and M. Devos (V.U.B.) are gratefully acknowledged for collecting the sea-ice cores. The authors thank also the National Institute of Polar Research of Japan for their efficiency in taking care of the samples to Tokyo airport, and M. Depasse of the Belgian embassy for his cooperation. This paper is a contribution to the Belgian scientific programme on Antarctica (Science Policy Office).

\section{REFERENCES}

Allison, I. 1979. Antarctic sea ice growth and oceanic heat flux. International Association of Hydrological Sciences Publication 131 (Symposium at Canberra 1979 - Sea Level, Ice and Climatic Change), 161-170.

Arnason, B. 1969. Equilibrium constant for the fractionation of deuterium between ice and water. J. Phys. Chem., 73, 3491-3494.

Cox, G.F.N. and W.F. Weeks. 1983. Equations for determining the gas and brine volume in sea-ice samples. J. Glaciol., 29(102), 306-316.

Lange, M.A., S.F. Ackley, P. Wadhams, G.S. Dieckmann, and H. Eicken. 1989. Development of sea ice in the Weddell Sea. Ann. Glaciol., 12, 92-96.

Maykut, G.A. 1978. Energy exchange over young sea ice in the central Arctic. J. Geophys. Res., 83(C7), 3646-3658.

Maykut, G.A. 1986. The surface heat and mass balance. In Untersteiner, N., ed. The geophysics of sea ice. New York, Plenum Press, 395-463. (NATO ASI B 146.)

Meerburg, A.J. 1968. Meteorology: Base Roi Baudouin, February 1966 to January 1967. Volume one: Surface observations, upper air observations. Brussels, EXANTAR (Expédition Antarctique Belgo-Néerlandaise 1966).

Nakawo, M. and N.K. Sinha. 1981. Growth rate and salinity profile of first-year sea ice in the High Arctic. $J$. Glaciol., 27(96), 315-330.

Souchez, R., J.-L. Tison, and J. Jouzel. 1987. Freezing rate determination by the isotopic composition of the ice. Geophys. Res. Lett., 14(6), 599-602.

Souchez, R., J.-L. Tison, and J. Jouzel. 1988. Deuterium concentration and growth rate of Antarctic first-year sea ice. Geophys. Res. Lett., 15(12), 1385-1388.

Tison, J.-L. and J. Haren. 1989. Isotopic, chemical and crystallographic characteristics of first-year sea ice from Breid Bay (Princess Ragnhild Coast - Antarctica). Antarctic Sc., 1(3), 261-268.

Weeks, W.F. and S.F. Ackley. 1986. The growth, structure, and properties of sea ice. In Untersteiner, N., ed. The geophysics of sea ice. New York, Plenum Press, 9-164. (NATO ASI B 146.) 